\title{
Impact of Knowledge Sharing Adoption on Universities' Virtual Learning Communities
}

\author{
Abdullah Alammari \\ University of Technology \\ Sydney, Australia; and Umm \\ Al-Qura University, Saudi \\ Arabia \\ a.alammari@student.uts.edu.au
}

\author{
Daniel Chandran \\ University of Technology \\ Sydney, Australia \\ daniel.chandran@uts.edu.au
}

\begin{abstract}
In new age, knowledge has become a significant source. Knowledge sharing is a substantial component of success in any organisation. In various organisations, knowledge sharing adoption is lacking, especially among academic staff working in Saudi universities. This paper investigates collectivism impact on knowledge-sharing factors among academics in Saudi e-learning communities. A conceptual model that will affect the knowledge sharing behaviour within the e-learning community in Saudi universities is proposed. Hypotheses have been accordingly developed. Data was collected in different Saudi public universities. Partial Least Square approach has been applied to analyse the data. The findings of this study provide key factors affecting the process of knowledge-sharing adoption between academic staff within the virtual learning communities in Saudi universities.
\end{abstract}

\section{Introduction}

Knowledge Management or "KM" is a new research area within the Arab countries and specifically in Saudi Arabia. Because Saudi Arabia has given great priority to change its society to knowledge-basedeconomy and knowledge-based-society, in recent times, Saudi Arabia has started to build multiple knowledge centres keeping in mind the end goal to broaden their economy resources from the natural resources productions only reliance to the knowledgebased-economy [57].

With regards to this study, the Saudi Ministry of Education has launched the national "LOR" project known as Learning Objects Repository "Maknaz" that aims to serve strategic arrangements towards the enhancements in knowledge growth and learning resources. In any case, there is a need to populate the Saudi national "LOR" "Maknaz" with the reusable learning electronic materials and digitalized contents [7] referred from [4].

There is no doubt that the E-learning communities do not have a coordinated knowledge management system that prompts learning contents creation, while the knowledge management practices and then procedures in an internet learning approach. Moreover, knowledge management strategies in e-learning offer Saudi e-learning communities with knowledge contents producing, reusing, sharing and filtering. Hence, "Maknaz" repository contents will be viably populated when knowledge sharing practices are embraced in Saudi e-learning environment.

The e-learning communities refer to the educational environments, which addresses learning needs of its individuals through PC-mediated correspondence. It is also referred to the "computer-supported knowledgebuilding communities" [55]. Idea of learning communities depends on the reflection that learning and knowledge are part of communities that share the values, beliefs and methods for doing things [19]. In this admiration, the knowledge is hard to isolate from practice; on the other way, the practice is inseparable from learning communities in which this practice occurs.

In the light of these reasons, universities in Saudi Arabia have begun to thoroughly consider the future of e-learning in their institutions. Research by [13] has proposed that with the new information innovations accessible, future of universities is in creating knowledge procedures and developing their knowledge production possibilities. As expressed in [31] there has been the rhetoric of utilizing e-learning to bolster the knowledge based-economy by proposing more extensive and diverse sorts of access for learning. As indicated by [34], the knowledge sharing is the primary 
part of the success in most organisations. Specifically, the academic organisations performance may not be capable and up to the market expectations because of their knowledge sharing absence. Recent research has demonstrated the key components that impact knowledge sharing reception in different organizational settings cited in [37], [54], [21], and [29]. Same as other organisations, universities as knowledge-based bodies have a tendency to depend on more on the sharing of knowledge. Nevertheless, a little research has explored the knowledge sharing adoption by the academic staff in academic institutions, particularly in Saudi universities e-learning communities context [34], $[4,5]$.

\subsection{Research problem}

This research paper investigates the different factors that influence the adoption of knowledge sharing activities in Saudi e-learning communities. The research attempts to address the following research question: (1) what are the factors that influence the adoption of knowledge sharing among academic staff in e-learning communities in Saudi universities? (2) What is the effect of collectivism on knowledge sharing factors towards staff attitude of knowledge sharing in e-learning communities in Saudi universities?

\section{Literature review}

A research explored that knowledge originates inside people or social frameworks (gatherings of people) [6]. Some recent researchers have grouped the knowledge management into organizational and individual dimensions [23]. The most frequent studied knowledge management organizational dimensions are top management support and leadership, information technology infrastructure, rewards and incentives [65], [9]. Other than the organizational dimensions, the most frequently discussed factors of individual dimensions are people self-motivation, and interpersonal trust [16], [24]. Literature shows that accessibility to a few distinctive knowledge management factors and the abundance of these factors impact the adequacy of the knowledge sharing behavior and attitude. For-instance, it is explored in [66] that a portion of the common utilized factors are self-motivation, and trust as discussed earlier. Various other factors that influence the knowledge sharing in organisations include the extrinsic motivational rewards, internal environment of the organisation, and the support from top management.

\subsection{Knowledge management organisational factors}

The literature review of this research has been done to discover the knowledge management organisational factors influencing the knowledge-sharing adoption and how the collectivism culture can influence these factors. It includes the organizational rewards, the knowledge sharing process, leadership support, IT infrastructure, behavioral intention and attitude, and subjective norms and collectivism culture. These factors are illustrated as:

Leadership refers to top management functions to make the knowledge management activities initiatives [30]. There is no doubt that leadership support has a key role in any knowledge management adoption activity in organisations [30], [26]. Various studies have affirmed that adoption of sharing staff experiences or practicing sharing their knowledge is essentially impacted by the level of top leadership reception for the same activities [43], [30], [49]. As cited in [65], the leaders' roles are imperative in boosting knowledge management conduct within their organisation. This implies that staff will probably take after their leaders when they urge them to share the knowledge.

Knowledge-sharing processes allude to the procedures of collecting and donating knowledge [49]. The Knowledge donation signifies the workers activities to disseminate their intellectual property in an organisation while knowledge collection refers to the representatives' activity requesting knowledge from each other keeping in mind the end goal to build the intellectual capital [49]. Knowledge sharing activity is a key process among other knowledge sharing processes including knowledge creation, exchange, dissemination and acquisition [30]. In various researches, the knowledge sharing has been portrayed as the stage that exists between "knowledge creation and information use of (KM) exercises [52], [1], [59]. The effective knowledge sharing processes in any organisation will facilitate the procedures to socially share knowledge between staff in order to easily generate knowledge contents that improves the creation of organizational knowledge growth and its intellectual capital [47].

Moving forward there is another factor "Reward system" that refers to incentives for the knowledge sharing endeavors [62]. The organizational rewards can be utilized to motivate individuals to arrange endeavors towards accomplishing organisational targets. Various researchers have contended that a reward energizes the workers; representatives like to play out their employment well, when they see rewards on successful accomplishment of task or activity [20], [33]. Thus, 
one of the imperative factors is to set up the right motivation, reward or motivational encouragements to urge individuals to apply and share knowledge. Offering motivating rewards to workers empower and fortify the positive conduct and culture required for successful knowledge sharing [39]. Research led by [34] in Malaysian university and its outcomes demonstrated that the rewards have a positive impact on the state of mind in the knowledge sharing contexts in terms of academics.

IT infrastructure refers to such technologies that are supporting communication among staff to help in the decision-making procedures. Information Technology is an empowering factor in the successful knowledge sharing framework. It has a crucial part in the knowledge sharing practice as it raises the level of knowledge sharing adoption. Moreover, IT is emphatically connected with the knowledge creation in different ways varies from knowledge flow and sharing to storing. In the light of infrastructure offered by IT, knowledge management platforms can be largely embraced to capture, create, deliver, and share boundless volume of knowledge contents within various organizations.

\subsection{Knowledge management individual factors}

In terms of individual dimensions, most frequently discussed factors are self-motivation and trust [16], [24]. Moreover, Knowledge-sharing is a key part of KM since it supports depository codification of accessible information in an organisation. Individual's interpersonal trust and self-motivation factors got solid emphasis from various researchers in affecting the achievement of knowledge sharing [3]. Organization managers consider a social norm that influences staff's knowledge sharing behaviour, and model their practice by influencing staff to imitate. In literature, various distinctive KM factors can impact the adequacy of knowledge sharing behavior and attitude. Some of the usually found factors are self-motivation and trust [66]. Research [30] studied six KM success factors that interface with each other, as opposed to an irregular accumulation of irrelevant factors.

Sharing knowledge successfully requires the top management support and positive social collaboration and trust among the individuals of company groups [36]. There should be an atmosphere of trust within the organization. It is a psychological feeling that if there is trust, there will be sense of security and performance of employees will be better; keeping in mind that the end goal that organisations is to build up an environment of trust where the members can willingly have the eagerness to share their knowledge and to work for the advantage of the whole community [15].
Another concept which is widely used in KM literature in connection to self-motivation is the 'self- efficacy'. Here the Self-efficacy' alludes to an individual's confidence in his/her own abilities. Also, it implies the amount of trust the members have in their own capacity to get success. The more the self-motivation a person has the more he will perform and the more he will share knowledge. So, a positive social collaboration of company members and administration support are important to share knowledge successfully.

\subsection{Culture}

Culture is defined in [67] as "the collective programming of the mind which distinguishes the members of one group or category of people from another". Hofstede's cultural dimensions show Saudi Arabia on individualism-collectivism (IDV) with an index score of 20, which means a high collectivistic society [68]. Cultural factors have been widely studied in information system research [68], [69], [71] and [72].

\subsection{Subjective norms}

The subjective norm is explored by [2] as the degree of the individual's observation that he or she can have, on whether individuals who are important to him or her consider a particular behaviour to be performed or not. It is the extent to which an individual considers the influence of others on that person to adopt a new technology or to perform a specific task [63]. Various researchers have discovered positive connections between the subjective norms and individual's attitude towards the behavioural intention to adopt a new system in an organisation [50]. Subjective norm is considered as a social related pressure on an individual to perform particular behavior under internal social consideration [64].

\subsection{Attitude and behavioural intention}

Attitude is negative or positive feeling that an individual has to keep in mind the end goal to complete a particular behavior [2]. Researchers have confirmed that the extent of intensity in people's attitude can affect the degree of occurrence for the behavioral intention. It is described as "physical tendency that is communicated by assessing a specific factor with some level of disfavor or favor [35]. Attitude is indeed a main variable for our study as it is a predetermining variable affecting performing any certain behavior with considering the subjective norms affecting the behavioural intention as well. It is contended in [46] that attitude of teachers' towards tolerating and 
utilizing technology is a key factor that decides the successful acknowledgment and utilization of IT framework among instructors. As indicated by [63], the attitude of teachers' is an important factor towards achievement of any activity to receive any innovation or framework in educational field. Subsequently, as attitude of instructors' significantly impacts the way toward deciding the utilization of any IT framework, it is needed to research their attitude towards embracing the e-learning framework for utilizing it for knowledge sharing practices among academic staff in the elearning communities in several Saudi educational institutions. The researcher defines the behavioral intention as the individual's perceived likelihood to engage in a given behavior [28]. Scholars argue that individual thoughts, beliefs beside his attitude are the co-determinants of any behavioral intention towards adopting new technology or system [25].

\section{Theoretical background and hypotheses development}

This research is based on theoretical background and hypotheses development to investigate the factors of knowledge sharing adoption in e-learning communities in Saudi universities, and proposes a model that will influence the process of the knowledge sharing inside the e-learning communities through the application of KM practices. In this way, the literature review on wide theoretical models for organizational and individuals KM factors and attitude towards behavioral intention was carried out in this study. These theories include the Theory of Reasoned Action (TRA) cited in [28], Theory of Planned Behavior (TPB) cited in [2], [28] and the Unified Theory of Acceptance and Use of Technology (UTAUT) model cited in [64]. With regards to predicting human behavior, Theory of Planned Behavior (TPB) and the Theory of Reasoned Action (TRA) are generally examined. Hypotheses propose that a people behaviour is anticipated by his or her behavioral intention, which is affected by his or her attitude towards a certain behavior, among different involving factors. TRA concentrates on foreseeing behavioral intention and actual behaviour. It depends on behavioral thoughts and beliefs and subjective norms as cited in [60], [44] and [14]. With regards to present research, authors have utilized TRA to foresee the actual use of knowledge sharing adoption in Saudi e-learning communities as being affected by the participants' behavioral intention goal, which thus relies on their subjective norms and attitude [12],[60].

Moreover, recent researches expressed that knowledge generates inside communities of people and have characterized KM into the organizational and individual dimensions. Conducted literature on KM with considering the Saudi context has revealed different factors including organizational factors: ( motivational rewards, the knowledge sharing process, leadership support, IT infrastructure); individual factors including (trust and self-motivation) as well as behavioral intention, attitude and subjective norms as illustrated in [8], [10], [32], [45]. In addition to these factors, the collectivism factor was embraced from Hofstede's (1980) since it is very relevant to the Saudi society. Figure 1 shows the research model.

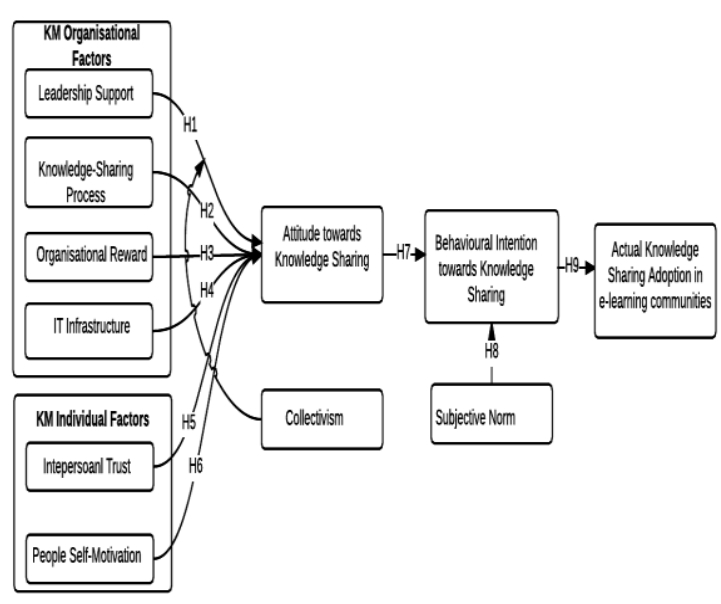

Figure 1. Research model

\subsection{Hypotheses}

\section{Knowledge management organizational factors}

In this case, the researchers have affirmed that leadership has a solid association with attitude of their representative. For instance, it has been highlighted that the leaders are imperative in sharing information and the staff are affected by the level of top administration engagement in knowledge sharing [11], [49], and [65]. This implies the leader's part in empowering workers for new practices which has an impact on the staff attitude towards receiving the practice, and this will influence representatives to have an inspirational disposition towards the knowledge sharing. Literature, likewise recommends that the rewards are successful factors which will make beneficial outcome on worker attitude about sharing the knowledge [33], [17]. What's more, [34] explored that rewards have a positive impact on attitude in the knowledge sharing in term of academics. The compelling utilization of $\mathrm{KM}$ is regularly taking into account the utilization of (IT) frameworks. Staff can share the knowledge by an Information Technology if they have being familiar with using the system in the 
right way as it was developed for. With our research purposed, following hypotheses are developed:

Hypothesis 1: Collectivism will moderate the relationship between Leadership Support and attitude toward knowledge sharing such that the relationship is strong for academics in Saudi universities' e-learning communities.

Hypothesis 2: Collectivism will moderate the relationship between Knowledge Sharing Process and attitude toward knowledge sharing such that the relationship is strong for academics in Saudi universities' e-learning communities.

Hypothesis 3: Collectivism will moderate the relationship between Organisational Reward and attitude toward knowledge sharing such that the relationship is strong for academics in Saudi universities' e-learning communities.

Hypothesis 4: Collectivism will moderate the relationship between IT Infrastructure and attitude toward knowledge sharing such that the relationship is strong for academics in Saudi universities' e-learning communities.

\section{Knowledge management individual factors}

One of the most important individual factor in terms of $\mathrm{KM}$ is "Trust" that prompts expanded knowledge sharing and upgrades the probability that the knowledge will be comprehended and then applied. Trust is specifically limited to the level of psychological security in knowledge sharing - the more trust amongst company members, the more sharing of knowledge [41]. There is a positive relationship amongst knowledge sharing and trust [3].

In KM, without the activity of members and the adjusting of the gathering and individual objectives, powerful knowledge sharing can't be guaranteed. This conviction is integral to how individuals think and carry on. Keeping in mind the end goal to accomplish an objective, a person needs to trust that it can be conceivable and he/she can achieve it [48]. Notwithstanding, to share the knowledge, it is insufficient that members have an intrinsic desire to share the knowledge, knowledge maker should likewise see that the knowledge can be effectively applied. The more self-motivation or efficacy individuals have, the more certainty they will have on their own insight and their ability. Intrinsic belief and motivation, prompts expanded profitability and supports the members of the group to share the more knowledge and therefore these hypotheses are developed:

Hypothesis 5: Collectivism will moderate the relationship between Interpersonal Trust and attitude toward knowledge sharing such that the relationship is strong for academics in Saudi universities' e-learning communities.

Hypothesis 6: Collectivism will moderate the relationship between People Self-Motivation and attitude toward knowledge sharing such that the relationship is strong for academics in Saudi universities' e-learning communities.

\section{Subjective norms}

The factor "Subjective norm" reflects the person impression of whether a certain behaviour is acknowledged by his circle of impact or not. A recent research has recognized that the subjective norm has a great impact on individual's behavior [2], [64]. In this way, the following hypothesis is developed.

Hypothesis 7: Subjective Norm (SN) of educators has a significant positive effect on their behavioural intention (BI) toward knowledge sharing adoption in Saudi universities' e-learning communities.

\section{Attitude and behavioural intention}

As indicated by [28], the attitude affects behavioral intention. The solid relationship amongst the behavior and attitude has gotten impressive empirical support as cited in [51], [18], and [38]. Literature demonstrates that individual's attitude with respect to knowledge sharing reflects their willingness to be required in the knowledge sharing adoption. Accordingly, the following hypotheses are proposed:

Hypothesis 8: Academics' Attitude (ATT) towards knowledge sharing adoption in Saudi universities' elearning communities has a significant positive effect on the behavioural intention (BI) toward knowledge sharing practices in e-learning communities in Saudi Arabia.

Hypothesis 9: Academics' Behavioural Intention (BI) towards knowledge sharing adoption in Saudi universities' e-learning communities has a significant positive effect on the actual adoption of knowledge sharing practices in e-learning communities in Saudi Arabia.

\section{Methodology}

This study has used quantitative method to collect numerical data from respondents in Saudi universities. The survey instrument is used to collect data. Data has been collected in major public universities in Saudi Arabia. This research adopts previously validated instruments in order to ensure the survey items are adequate. The survey has been developed in English. A translated Arabic version has been included in the survey. The five point Likert scale (1=strongly 
disagree to $5=$ strongly agree) is used as it is one of the most commonly used techniques of scaling responses in a survey design. Survey was sent to 500 participants and 200 participated in the survey. After removing incomplete responses, a total of 160 responses have been used for data analysis. The research model has been tested using Partial Least Squares- Structural Equation Modelling (PLS-SEM) statistical technique using SmartPLS version 3 [53]. Partial Least Squares approach is used to test theoretical models and to understand the simultaneous modelling of relationships among various independent and dependent factors.

\subsection{Data analysis}

Descriptive analysis shows that $60 \%$ of the participants are male and $40 \%$ are female. $55 \%$ are in the age bracket of 26-35 years, 30\% participants are $36-45$ years and $15 \%$ are above 45 years. $51 \%$ of the respondents hold Master degree, followed by bachelor's degree with $35 \%$ and $14 \%$ hold doctoral degree. $45 \%$ of participants have more than 5 years of work experience, followed by $30 \%$ between 3-5 years; $25 \%$ of the participants have work experience of 1-3 years.

The data has been analysed using Partial Least Squares (PLS) approach, which is considered to be suitable for this study. PLS allows the investigators to simultaneously evaluate structural path coefficients and measurement model parameters. It allows formative and reflective variables to be tested together [22]. In our research model all factors except subjective norms are modelled as reflective indicators because they are viewed as effects of latent variables. The subjective norms is formative in nature [27], which is not interchangeable because it is a multidimensional variable, which means change in one indicator does not necessarily denote change in other indicator.

\subsubsection{Reliability and validity assessment}

The measurement model is assessed by internal consistency, convergent validity and discriminant validity. Convergent and discriminant validity are calculated using items loadings were at least 0.70 and the square root of the average variance extracted (AVE) from its factor indicators, which was at least 0.70 and was greater than that factor correlation with other factors. Subjective norm is a formative construct that cannot be examined in this procedure. However, the validity of subjective norm has been examined using outer weights that are significant at $\mathrm{p}$ value < 0.05 . In addition for the reliability of formative indicator, the variance inflation factor (VIF) value is less than 5 , which means there is no multicollinearity.
Table 1 shows the average variance extracted (AVE), Cronbach's reliability, composite reliability and the AVE of all constructs values exceed the recommended value of 0.70 . An independent t-test was conducted to compare the culture (collectivism) differences which was significant at $\mathrm{p}<0.05$.

Table 1. Reliability, correlation, and discriminant validity of constructs.

\begin{tabular}{|c|c|c|c|c|c|c|c|c|c|c|c|c|c|c|}
\hline & AVE & Calpha & $C R$ & LS & KSP & $\mathrm{OR}$ & IIIF & IPT & PSM & SN & ATT & BI & $\begin{array}{l}\text { KS } \\
\text { A }\end{array}$ & $\mathrm{Col}$ \\
\hline LS & 0.82 & 0.89 & 0.83 & 0.90 & & & & & & & & & & \\
\hline KSP & 0.85 & 0.86 & 0.88 & 0.25 & 0.92 & & & & & & & & & \\
\hline $\mathrm{OR}$ & 0.81 & 0.82 & 0.85 & -0.39 & -0.03 & 0.90 & & & & & & & & \\
\hline ITIF & 0.88 & 0.88 & 0.88 & 0.50 & -0.00 & -0.23 & 0.93 & & & & & & & \\
\hline $\mathrm{IPT}$ & 0.81 & 0.87 & 0.65 & 0.33 & 0.08 & -0.13 & 0.15 & 0.90 & & & & & & \\
\hline PSM & 0.80 & 0.77 & 0.71 & 0.51 & 0.70 & 0.26 & 0.21 & 0.20 & 0.89 & & & & & \\
\hline SN & NA & $\mathrm{NA}$ & $\mathrm{NA}$ & 0.52 & 0.08 & -0.23 & 0.50 & 0.31 & 0.12 & 1 & & & & \\
\hline ATT & 0.83 & 0.83 & 0.88 & -0.03 & -0.03 & 0.03 & 0.02 & 0.08 & 0.13 & 0.05 & 0.91 & & & \\
\hline BI & 0.83 & 0.84 & 0.85 & 0.53 & -0.08 & -0.28 & 0.88 & 0.70 & 0.26 & 0.59 & 0.02 & 0.91 & & \\
\hline KSA & 0.88 & 0.83 & 0.88 & -0.32 & 0.09 & -0.33 & 0.01 & 0.09 & 0.04 & 0.07 & 0.08 & 0.00 & 0.93 & \\
\hline $\mathrm{Col}$ & 0.81 & 0.84 & 0.85 & 0.05 & 0.02 & 0.06 & 0.02 & 0.09 & 0.01 & 0.02 & 0.02 & 0.10 & 0.02 & 0.90 \\
\hline \multicolumn{15}{|c|}{ 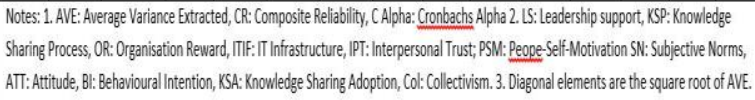 } \\
\hline
\end{tabular}

\subsubsection{Structural model testing}

The structural model testing is conducted to test the proposed hypotheses. The significance of the paths between construct is analysed by t-test calculated with the bootstrapping technique at a 5 percent significance level. Moreover, the moderating effects were performed using the product indicator approach which refers to the product of each item of the independent variable with each item of the moderator variable [73]. The coefficients of the causal relationships between factors are determined by the significance of the path coefficients and the $\left(\mathrm{R}^{2}\right)$ variance of the dependent construct. Table 2 shows the path co-efficient mean, standard deviation and t-statistics and p-value for each of the proposed hypotheses. The recommended $t$ values are $\mathrm{t}>1.96$ at $\mathrm{p}<0.05, \mathrm{t}>2.576$ at $\mathrm{p}<0.01, \mathrm{t}>$ 3.29 at $\mathrm{p}<0.001$ for two-tailed tests. Figure 2 shows the path testing. 
Table 2. Hypotheses testing.

\begin{tabular}{|c|c|c|c|c|c|c|}
\hline & Path & Path coefficent mean & StDev & T statistics & P value & Supported? \\
\hline $\mathrm{Hl}$ & $\mathrm{LS}^{*} \mathrm{Col}->\mathrm{ATT}$ & 0.22 & 0.01 & 1.98 & $0.002^{*}$ & Yes \\
\hline $\mathrm{H} 2$ & KSP* $\mathrm{Col}->$ ATT & 0.29 & 0.02 & 2.65 & $0.000^{* * *}$ & Yes \\
\hline $\mathrm{H} 3$ & $\mathrm{OR}^{*} \mathrm{Col}->\mathrm{ATT}$ & 0.10 & 0.03 & 1.10 & 0.25 & No \\
\hline $\mathrm{H} 4$ & ITIF* ${ }^{*} \mathrm{Ol}->$ ATT & 0.24 & 0.04 & 1.97 & $0.003^{*}$ & Yes \\
\hline $\mathrm{H} 5$ & IPT*Col $>$ ATT & 0.21 & 0.02 & 2.29 & $0.000^{* * *}$ & Yes \\
\hline H6 & $\mathrm{PSM}^{*} \mathrm{Col}->\mathrm{ATT}$ & 0.19 & 0.01 & 1.45 & 0.336 & No \\
\hline $\mathrm{H} 7$ & ATT-BI & 0.24 & 0.03 & 1.99 & $0.002^{*}$ & Yes \\
\hline H8 & SN-> BI & 0.55 & 0.04 & 3.90 & $0.000^{* * *}$ & Yes \\
\hline H9 & $\mathrm{BI} \bullet \mathrm{KSA}$ & 0.42 & 0.07 & 2.10 & $0.000^{* * *}$ & Yes \\
\hline \multicolumn{7}{|c|}{$\begin{array}{l}\text { Notes: } \\
\text { - STDEv: Standard deviation, LS: Leadership support, KSP: Knowledge Sharing Process, OR: Organination Reward, } \\
\text { ITIFI IT Infrastructure, SN: Subjective Norms, ATT: Attitude, BI: Behavioural Intention, KSA: Knowledge Sharing } \\
\text { Adoption, }\end{array}$} \\
\hline
\end{tabular}

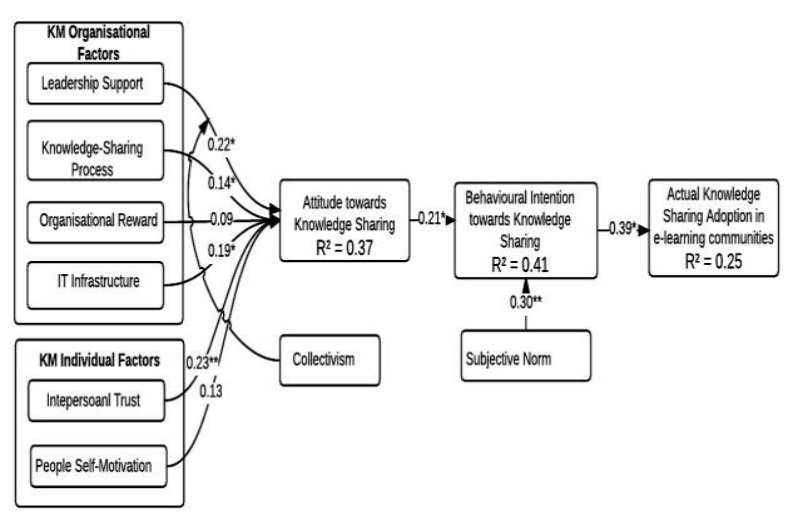

Figure 2. Path testing

As shown in the Figure 2, the results confirm the relationship in significance for all hypotheses at $\mathrm{p}<0.05$, except $\mathrm{H} 3$ where the relationship organisation reward and attitude is insignificant. $\mathrm{R}^{2}=0.37$ indicates 37 percent variance in attitude. For the behavioural intention $\mathrm{R}^{2}=0.41$ indicates 41 percent variance. $\mathrm{R}^{2}=0.25$ indicates 25 percent variance in actual knowledge sharing adoption in Saudi e-learning communities.

\section{Findings and discussion}

According to the path testing as shown in Figure 2, the order of significance among the knowledge management organisational factors that have a significant effect is "leadership support", followed by "IT infrastructure", "knowledge sharing process" and "organisational reward". Statistically significant support was found for collectivism effects on the relationship between 'leadership' and staff attitude towards knowledge sharing adoption in Saudi e- learning communities. It can be interpreted that academic staff share information and insights throughout the organization and have considerable influenced by the degree of top management adoption, which in turn from collectivism culture values. This is consistent with [65], [30]. The organisation promotes a knowledge sharing culture that focuses on participation. Information technology infrastructure plays a successful role in e-learning adoption. The results also shows significant collectivism effects on the relationship between 'Information technology infrastructure' and staff attitude towards knowledge sharing adoption in Saudi e-learning communities. In addition, giving incentives to employees helps to stimulate and reinforce the positive attitude. However, our results show the insignificant collectivism effect on "organisational reward" and staff attitude. This could be attributed to the fact that the data had been collected in Saudi Arabia and all the participants in the survey are Muslims. As per Islamic belief, rewards are encouraged by religion which is consistent with Prophet Mohammed's recommendation as reported by Ibn Mas`ud that The Prophet (PBUH) said: "Envy is permitted only in two cases: a man whom Allah gives wealth, and he disposes of it rightfully, and a man to whom Allah gives knowledge which he applies and teaches it". Hence participants are not accepting "organisational reward" as an important organisational factor in knowledge sharing. In addition, the reason behind the significance of "knowledge sharing process" is that sharing more accurate data and timely information with others is one of the biggest advantages towards e-learning communities. The results also confirm that individual attitude is the key factor of behavioural intention to adopt actual knowledge sharing adoption in Saudi e-learning communities. This is in line with related studies [40], [61].

The findings show the order of significance among knowledge-sharing individual factors is 'interpersonal trust' followed by 'people self-motivation'. This indicates 'interpersonal trust' is more likely to be associated with staff attitude towards knowledgesharing adoption. Saudi Arabia is a high collectivistic society as found in [67] and thus people form strong relationships where everybody takes responsibility for fellow members of their group. As a result, people prefer to communicate and establish interpersonal trust with known bodies. This shows knowledge-sharing is expected to be more in e-learning communities where there is a culture of trust amongst the staff members. Also, when the staff motivate oneself, they are likely to contact more and share knowledge, which leads to the generation of more knowledge. The results are consistent with [41,42] and [3]. 
The results also confirm that staff attitude and subjective norm is the key factor of behavioral intention to adopt actual knowledge-sharing adoption in Saudi e-learning communities. In the context of the current study, the actual use of knowledge-sharing adoption in Saudi e-learning communities is influenced by the staff behavioural usage intention, which in turn depends on the users' attitude and the subjective norms. The results are consistent with [58], [41] and [56].

\section{Conclusion and implication}

The study has fulfilled its main aim that was to examine the key factors that influence the adoption of knowledge sharing activities in Saudi universities' elearning communities. Data was collected from various public universities in Saudi Arabia and total of 160 responses were used for analyses. Partial least square approach was used to test the hypotheses of the study. The results indicated that among knowledge management organisational factors, 'leadership support', 'knowledge sharing process' and 'IT infrastructure' is positively and significantly related to staff knowledge sharing attitude. However 'organization rewards' did not significantly affect attitude. In addition, among knowledge management individual factors, 'interpersonal trust' is positively supported, while 'people self-motivation' doesn't have a positive effect on staff knowledge sharing attitude. Among other factors, subjective norm and attitude significantly impact 'behavioural intention' toward knowledge sharing adoption in the Saudi universities' e-learning communities.

Concerning implications from a theoretical perspective, this study contributes to the literature by presenting a proposed knowledge sharing adoption model in the academic context towards the e-learning communities. Practically, therefore, in an effort to make academic staff to adopt knowledge sharing practices, Saudi universities should implement supportive knowledge management practices to build actual knowledge sharing practices in the organization. As a result, e-learning stakeholders will gain advantages from knowledge management practices to share what they create and capture which will maximize the community's knowledge resulting in more production for the open educational resources and organization goals achievement as well [5].

\subsection{Limitation and future research}

Like any research this study has limitations. First, the data collection was restricted to academic staff in public universities in Saudi Arabia, which may affect the generalization of the study. Second, this study did not cover all aspects of knowledge sharing adoption. Third, this study did not consider the type of knowledge sharing. Thus, this is an area for future research to consider.

\section{References}

[1] Abdel-Aziz, A. S., \& Kamel, M. H. (2012). The Impact of Organizational Information on Knowledge Management Practices. International Journal of Business and Social Science, 3(24), 121-126. -84.

[2] Ajzen, I. (1991). The theory of planned behavior. Organizational Behavior and Human Decision Processes, 50, $179-211$.

[3] Al-Alawi, A.I., Al-Marzooqi, N.Y. and Mohammed, Y.F. 2007, Organizational culture and knowledge-sharing: critical success factors, Journal of Knowledge Management, 11, 2, pp.22-42.

[4] Alammari, A. M., \& Chandran, D. 2014, 'Populating Contents of the Saudi eLearning Objects Repository "Maknaz" from Information Technology \& Knowledge Management Perspective', In 2nd Asia-Pacific Conference on Computer Aided System Engineering-APCASE 2014, Bali, Indonesia - 10-12 February 2014, APCASE Foundation, pp. 10-13.

[5] Alammari, A.M. \& Chandran, D. 2013, 'The Adoption of Knowledge Management and Net Generation characteristics in E-Learning Communities in Saudi Arabia', Vision 2020: Innovation, Development Sustainability, and Economic Growth, Vienna, Austria 27-28 June 2013, June 2013 in Proceedings of the 21st International Business Information Management Association Conference (IBIMA), IBMA Publishing, Norristown, PA USA, pp. 818-823.

[6] Alavi, M., Kayworth, T.R. and Leidner, D.E. 2005, An Empirical Examination of the Influence of Organizational Culture on Knowledge Management Practices, Journal of Management Information Systems, 22, 3, pp.191-225.

[7] Almegren, A. and Yassin, S. Z. 2013. Learning Object Repositories in e-Learning: Challenges for Learners in Saudi Arabia. The European Journal of Open, Distance and ELearning, June, 26.

[8] Argote, L. and Ingram, P. 2000, 'Knowledge transfer: a basis for competitive advantage in firms', Organizational Behavior and Human Decision Processes, Vol. 82, No. 1, 150-169.

[9] Artail, H.A. 2006, Application of KM measures to the impact of a specialized groupware system on corporate productivity and operations, Information \& Management, 43, 4, pp.551-564. 
[10] Bartol, K.M. and Srivastava, A. 2002, 'Encouraging knowledge sharing: The role of organizational reward systems', Journal of Leadership and Organizational Studies, vol. 9, no. 1, pp. 64-76.

[11] Bain, G. Mann, L. Atkins, L. and Dunning. J. (2005), "R\&D Project Leaders: Roles and Responsibilities" Leadership, Management, and Innovation in R\&D Project Teams, pp. 49-70.

[13] Barnett, R. (2000a), "Realizing the University in an age of super complexity," Society for Research into Higher Education and Open University Press.

[14] Benham, H.C. and Raymond, B.C. (1996), "'Information technology adoption: evidence from a voice mail introduction", ACM SIGCPR Computer Personnel, Vol. 17 No. 1, pp. 3-25.

[17] Bock, G.W. and Kim, Y.G., (2002). Breaking the Myths of Rewards: An Exploratory Study of Attitudes about Knowledge Sharing. Information Resources Management Journal , 15 (2), $14-21$

[19] Bransford, D., Brown, A., \& Cocking, R. (1999). How People Learn: Brain, Mind, Experience and School.

[20] Cameron, J. \& Pierce, W.D. 1994, 'Reinforcement, reward, and intrinsic motivation: A meta-analysis', Review of Educational Research, vol. 64, no. 3, pp. 363.

[21] Chatzoglou, P.D. and Vraimaki, E. (2009), "Knowledgesharing behaviour of bank employees in Greece", Business Management Journal, Vol. 15 No. 2, pp. 245-266

[23] Connelly, C.E. and Kelloway, K. E. 2003, 'Predictors of employees' perceptions of knowledge sharing cultures', Leadership and Organization Development Journal, vol. 24, no. 5, pp. 294-301.

[24] Davenport, T.H., De Long, D.W. and Beers, M.C. 1998, Successful knowledge management projects, Sloan Management Review, 39, 2, pp.43-58.

[25] Davis, F.D. 1989, 'Perceived Usefulness, Perceived Ease of Use, and User Acceptance of Information Technology', MIS Quarterly, vol. 13, no. 3, pp. 319-40.

[26] DeTienne, K.B., Dyer, G., Hoopes, C. and Harris, S. (2004) Toward a Model of Effective Knowledge Management and Directions for Future Research: Culture, Leadership, and CKOs, Journal of Leadership \& Organizational Studies, 10, 4, 26-43.

[27] Eckhardt, A. Laumer, T. Weitzel, T. (2009), "Who influences whom? Analyzing workplace referents' social influence on IT adoption and non-adoption," Journal of Information Technology, vol.24, pp. 11-24

[28] Fishbein, M. \& Ajzen, I. 1975, Belief, attitude, intention, and behavior :an introduction to theory and research, Addison-Wesley Pub. Co., Reading, Mass.
[29] George, J. (2004), "The theory of planned behaviour and Internet purchasing”, Internet Research, Vol. 14 No. 3, pp. 198-212.

[30] Gupta, A. K., \& Govindarajan, V. (2000). Knowledge management's social dimension: Lessons from Nucor Steel. Sloan Management Review, 42(1), 71-80.

[31] Hodgson, V. E. (2002), "The European Union and elearning: an examination of rhetoric, theory and practice", Journal of Computer Assisted Learning, 18, 240-252.

[33] Jarvenpaa, S.L. and Staples, D.S. (2000), "The use of collaborative electronic media for information sharing, an exploratory study of determinants", Journal of Strategic Information Systems, Vol. 9 No. 2, pp. 129-154.

[34] Jolaee, A. Md Nor, K. Khani, N, Md Yusoff, R. (2014), "Factors affecting knowledge sharing intention among academic staff", International Journal of Educational Management, Vol. 28 Iss: 4, pp.413 - 431

[35] Kanchanatanee, K., Suwanno, N. and Jarernvongrayab, A. (2014). Effects of Attitude toward Using, Perceived Usefulness, Perceived Ease of Use and Perceived Compatibility on Intention to Use E-Marketing. jmr, 6(3), p.1

[36] Kharabsheh, R.A. 2007, 'A model of antecedents of knowledge sharing', Electronic Journal of Knowledge Management, vol. 5, no. 4, pp. 419-26.

[37] Kim, S. and Lee, H. (2006), "The impact of organizational context and information technology on employee knowledge-sharing capabilities", Public Administration Review, Vol. 66 No. 3, pp. 370-385.

[38] Kolekofski, J.K.E. and Heminger, A.R. (2003), "Beliefs and attitudes affecting intentions to share information in an organizational setting", Information and Management, Vol. 40 No. 6, pp. 521-532.

[41] Lin, C. 2006, To Share or Not to Share: Modeling Tacit Knowledge Sharing, Its Mediators and Antecedents. J Bus Ethics, 70(4), 411-428. http://dx.doi.org/10.1007/s10551006-9119-0

[42] Liu, Y., \& DeFrank, R. 2013, Self-interest and knowledge-sharing intentions: the impacts of transformational leadership climate and HR practices. The International Journal of Human Resource Management, 24(6), 1151-1164. http://dx.doi.org/10.1080/09585192.2012.709186

[43] MacNeil, C. M. (2004). Exploring the supervisor role as a facilitator of knowledge sharing in teams. Journal of European Industrial Training, 28(1), 93-102.

[44] Mao, E. and Palvia, P. (2006), "Testing an extended model of IT acceptance in the Chinese cultural 
context',ACM SIGMIS Database, Vol. 37 Nos 2/3, pp. 20 32 .

[45] McDermott, R. 1999, 'Learning across teams', Knowledge Management Review, vol. 8, no. 3, pp. 32-6.

[46] Moses, P., Wong, S., Bakar, K. \& Mahmud, R. 2013, 'Perceived Usefulness and Perceived Ease of Use: Antecedents of Attitude Towards Laptop Use Among Science and Mathematics Teachers in Malaysia', Asia-Pacific Education Researcher (Springer Science \& Business Media B.V.), vol. 22, no. 3, pp. 293-9.

[47] Nonaka, I and Konno, N (1998) The Concept of 'Ba': Building a Foundation for Knowledge Creation, California Management Review, 40(3), Spring 1998, pp. 40-54.

[48] Ormrod, J.E. (2006). Educational Psychology: Developing Learners $\left(5^{\text {th }} \mathrm{ed}\right)$. Pearson/Merrill: Prentice Hall, Upper Saddle River, NJ.

[50] Pan, C. C., \& Sivo, S., \& Brophy, J.(2003). Students' Attitude in a Web-enhanced Hybrid Course: A Structural Equation Modeling Inquiry. Journal of Educational Media \& Library Sciences, 41(2), 181-194

[51] Pavlou, P.A. and Fygenson, M. (2006), "Understanding and predicting electronic commerce adoption, an extension of the theory of planned behaviour", MIS Quarterly, Vol. 30 No. 1, pp. 115-143.

[52] Rajiv, S., \& Sanjiv, S. (2005). Knowledge Management Using Information Technology: Determinants of Short-Term Impact on Firm Value.Decision Sciences, 36(4),531-567. http://dx.doi.org/10.1111/j.1540-5414.2005.00102.x

[54] Ryu, S., Ho, H.S. and Han, I. (2003), "Knowledge sharing behaviour of physicians in hospitals", Expert Systems with Applications, Vol. 25 No. 1, pp. 113-122.

[55] Scardamalia, M., \& Bereiter, C. (1996). Computer support for knowledge-building communities. In $\mathrm{T}$. Koschmann (Ed.), CSCL: Theory and Practice of an Emerging Paradigm. Mahwah, NJ: Lawrence Erlbaum Associates.

[56] Seba, I., Rowley, J., \& Lambert, S. (2012). Factors affecting attitudes and intentions towards knowledge sharing in the Dubai Police Force. International Journal of Information Management, 32(4), 372-380.

[57] Shin, J., Lee, S. \& Kim, Y. 2012, 'Knowledge-based innovation and collaboration: a triple-helix approach in Saudi Arabia', Scientometrics, vol. 90, no. 1, pp. 311-26.

[58] Sivo, S.A., Cheng-Chang Pan \& Hahs-Vaughn, D. 2007, 'Combined longitudinal effects of attitude and subjective norms on student outcomes in a web-enhanced course: A structural equation modelling approach', British Journal of Educational Technology, vol. 38, no. 5, pp. 861-75.
[59] Sook-Ling, L., Choo-Kim, T. \& Razak, S.F.A. 2013, 'The Knowledge Management Activities for Achieving Competitive Advantage: A Conceptual Framework', International Journal of Business and Management, vol. 8, no. 23 , pp. 1-12.

[60] Sureena Matayong \& Ahmad Kamil Mahmood 2013, 'The review of approaches to knowledge management system studies', Journal of Knowledge Management, vol. 17, no. 3, pp. 472-90.

[61] Swart, J., Kinnie, N., van Rossenberg, Y. and Yalabik, Z. (2014) 'Why should I share my knowledge? A multiple foci of commitment perspective', Human Resource Management Journal, doi: 10.1111/1748-8583.12037.

[62] Syed-Ikhsan, S., \& Rowland, F. (2004). Knowledge management in a public organization: A study on the relationship between organizational elements and the performance of knowledge transfer. Journal of Knowledge Management, 8(2), 95-111.

[63] Teo, T., Lee, C.B. \& Chai, C.S. 2008, 'Understanding pre-service teachers' computer attitudes: applying and extending the technology acceptance model', Journal of Computer Assisted Learning, vol. 24, no. 2, pp. 128-43.

[64] Venkatesh, V., Morris, M.G., Davis, G.B. \& Davis, F.D. 2003, 'User Acceptance of Information Technology: Toward a Unified View', MIS Quarterly, vol. 27, no. 3, pp. 425-78.

[65] Wong, K.Y. (2005) Critical success factors for implementing knowledge management in small and medium enterprises, Industrial Management + Data Systems, 105, 3/4, pp.261-279.

[66] Xyeo, R., \& Gold, J. 2014, Knowledge sharing attitude and behaviour in Saudi Arabian organisations: why trust matters. International Journal of Human Resources Development And Management,14(1/2/3), 97

[67] Yhofstede, G., Hofstede, G. J., and Minkov, M. 2010. Cultures and Organizations: Software of the Mind, Intercultural Cooperation and Its Importance for Survival (3rd ed.). McGraw-Hill.

[69] Yan, D., and Kim, S. 2008. "Effects of National Culture on the Development of Consumer Trust in Online Shopping," Seoul Journal of Business (14:1).

[70] Zganguly, B., Dash, S. B., and Cyr, D. 2010. "The Effects of Website Design on Purchase Intentionin Online Shopping: The Mediating Role of Trustand the Moderating Role of Culture," Int. J. Electronic Business (8:4/5), pp. 302329.

[72] Zyoon, C. 2009. "The Effects of National Culture Values on Consumer Acceptance of E-Commerce: Online Shoppers in China," Inf. Manage. (46:5), pp. 294-301. 